\title{
Degradation of a Grinding Wheel when Grinding Cermet Materials and Its Influence on the Grinding Process
}

Tomas Baksa, Pavel Adamek, Ondrej Hronek, Miroslav Zetek

Faculty of Mechanical Engineering, University of West Bohemia. Univerzitni 8, 30614 Pilsen. Czech Republic. E-mail: baksa@rti.zcu.cz, adamek@rti.zcu.cz, hroneko@rti.zcu.cz,mzetek@rti.zcu.cz

\begin{abstract}
This article deals with the experimental grinding of cermet materials. Two types of cermet materials from different suppliers were ground under constant grinding conditions using a diamond grinding wheel. The main aim was to determine the influence of the grinding on the degradation of the grinding wheel and changes in the grinding process. Both types of cermet were ground with the same strategy and the same number of passes. The grinding wheel was analysed during grinding using an optical scanning device to observe the changes on the grinding wheel surface. Clogging and wear of the grinding wheel occurred on the surface as the amount of material removed increased. All grinding tests were carried out without dressing or truing of the grinding wheel. Degradation of the grinding wheel had a big influence on the grinding process in terms of the spindle load during grinding. The roughness of the ground surface was also measured using the optical scanning device. The results from this work will be used for further research of cermet grinding.
\end{abstract}

Keywords: Grinding, Cermet, Grinding wheel, Clogging, Spindle load

\section{Introduction}

The development of cutting tools is important for increasing productivity in manufacturing technologies. New cutting tools increase productivity through a higher cutting tool life and higher production speed. A basic parameter of each cutting tool is the material it is made of, which affects its behaviour during the cutting process. The developments in cutting tool materials allow us to use modern hard materials such as ceramics, cubic boron nitride or cermet. The grinding process is the main process in the production of solid cutting tools for obtaining the required geometry of the cutting tool. Grinding is also a necessary finishing process for many engineering parts. The appropriate selection of grinding conditions and strategies is necessary to ensure the high quality of the ground surface and the stability of the grinding process. The influence of different cutting parameters on surface quality has been investigated in many studies [7, 8]. It can be very problematic in the case of hard and difficult-tocut materials such as cermet. There are many problems associated with grinding cermet, such as high grinding wheel wear, high heat generation, clogging of the wheel, high cutting forces, etc. In order to minimize these problems we must first understand the whole process of grinding cermet.

A diamond grinding wheel is commonly used for grinding cermet [9]. The influence of the different cutting conditions on the cutting forces and the surface roughness during grinding cermet was described in $[11,13]$. There are two reasons for a grinding wheel losing its grinding ability while grinding cermet. The first is the dulling of the abrasive grains which occurs because of the gradual wear of the grinding wheel. This phenomenon is quite common and cannot be completely eliminated. The second reason is the clogging of the grinding wheel which is caused by cermet particles sticking to the grinding wheel surface. In research [1] it was found that chips during grinding are formed more by crushing than by cutting of cermet. High pressure acting between the diamond and the cermet causes crack formation which then causes the cermet particles to be broken off. These particles stick to the grinding wheel and decrease the grinding ability of the wheel. To restore grinding ability, a process such as dressing and truing is needed. However, these additional processes are both expensive and time-consuming. Research [10] deals with improvements to the dressing process for diamond grinding wheels.

Experimental grinding in terms of heat generation is described in research [2]. It was found that heat in the contact area between the wheel and the workpiece increases as the volume of removed material increases. High temperature causes boiling of the cooling fluid which leads to a loss of the cooling capability. When the temperature reaches approximately $150{ }^{\circ} \mathrm{C}$ a phenomenon known as 'burnout' occurs which causes a rapid rise in temperature to over $400{ }^{\circ} \mathrm{C}$. High temperature leads to a decrease in the strength of the diamond grains and the bond of the grinding wheel. This causes rapid wear of the grinding wheel because of the abrasive grains breaking and coming loose. Theoretical analysis of the contact area between grinding wheel surface and workpiece is described in [12]. Temperature in the contact area also affects the quality of the finished surface. The impact of cutting parameters on the temperature of grinding is described in [6].

Selection of an appropriate grinding wheel for grinding a specific material is as important as the selection of the appropriate cutting tool for productive cutting. Research [3] deals with the influence of different grinding wheels on grinding power and G-ratio during grinding of cermet materials. It was found that a grinding wheel with harder and finer diamond grains (D64) achieves a lower normal force and requires lower power. It was also found that grinding of cermet using a finer grinding wheel (D64) achieves a higher G-ratio compared to a coarse grinding wheel (D107). This finding is opposite to the grinding of carbides, and it shows that we cannot use the same 
knowledge as for grinding carbide. The coarse grinding wheel shows a higher degree of degradation due to less active diamond particles involved in the cutting process. Research [4] tested an even finer diamond grinding wheel (D46) for grinding a cermet cutting tool, but it gave worse results in the following cutting test, where the tool showed higher wear than a cermet tool ground using a medium-fine grain grinding wheel (D64). Very small grains cause heat load during grinding due to high friction and less depth of grain penetration. This can cause damage to the cutting edge which results in higher wear intensity during cutting. On the other hand, big grains on the grinding wheel can cause tear outs of the cutting edge and less cutting stability. The results from these tests $[3,4]$ confirm the recommendations of the grinding wheel manufacturers that the optimum grain size for a grinding wheel for grinding cermet and carbides is medium-fine D64.

High temperatures, temperature gradients and thermomechanical stress produced during the grinding of cermet result in surface damage in the form of micro-cracks. The relationship between the grinding process and the wear behaviour of the cutting tool was observed in [5], where cutting wedges were ground from cermet and carbide. Cermet cutting wedges show better results in terms of wear than carbide cutting wedges, because of their higher hardness at higher temperatures and the better oxidation resistance of cermet. It was found that these properties are affected by the $\mathrm{TiC} / \mathrm{TiN}$ ratio in the cermet.

This work is focused on the influence of the material removal volume on the degradation of the grinding wheel during the grinding of two different cermet materials. The grinding wheel was measured and analysed during grinding using an optical scanning device. The spindle load was monitored as an indicator of the influence of the degradation of the grinding wheel on the grinding process. The roughness of the ground surface was also measured. This research will be used in further experiments to better understand the grinding of cermet.

\section{Grinding details}

Two different cermet materials from different suppliers were used for the grinding test to observe the effect of both materials on the grinding process and the degradation of the grinding wheel. The materials were analysed using electron microscopy to observe the structure and chemical composition (Tab. 1). The specification of both materials declared by the supplier is given in Tab. 2 . Grinding was performed on a CNC 5-axis tool grinder with a diamond grinding wheel. The grinding wheel was of a standard shape 1A1 with medium small grit size. High quality diamond with medium-soft bond was used for the high cutting capacity of the wheel. Tab. 3 shows the specification of the grinding wheel. The same grinding wheel was used for all the grinding tests. The grinding material was in the form of a cermet rod with a diameter of $8 \mathrm{~mm}$.

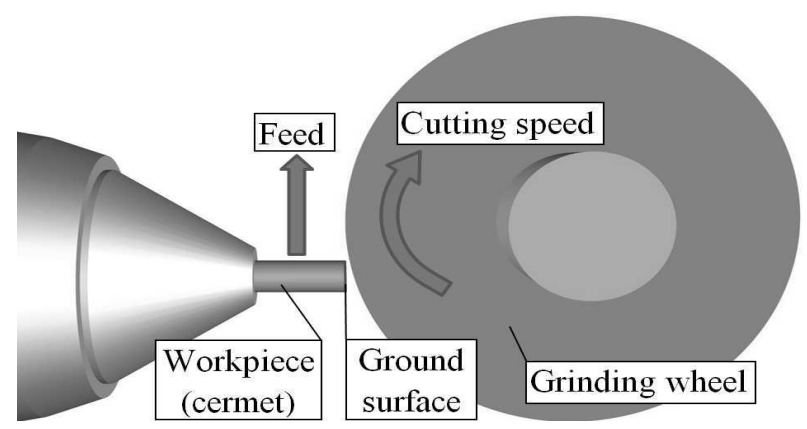

Fig. 1 Strategy of grinding

The material was ground on the front of the rod by the periphery of the grinding wheel. The width of the grinding wheel must be greater than $8 \mathrm{~mm}$ to ensure the cutting of the whole diameter. The strategy of grinding is shown in Fig. 1. Grinding was performed under constant cutting conditions with a constant depth of cut of $0.5 \mathrm{~mm}$ per pass. The total volume of material removed was determined by the total number of passes. High-performance grinding fluid was used during grinding to ensure the better lifetime of the grinding wheel and the stability of the grinding process. The strategy of down grinding was used to ensure lower temperatures. The cutting parameters are specified in Tab. 4. No dressing or truing processes were included during the grinding of each material in order to observe the influence of the grinding on the grinding wheel. Spindle load was monitored during grinding to observe the changes in the grinding process.

Tab. 1 Chemical composition of cermets

\begin{tabular}{|c|c|c|c|c|c|c|c|c|c|c|}
\hline & $\mathrm{Ti}[\%]$ & $\mathrm{W}[\%]$ & $\mathrm{C}[\%]$ & $\mathrm{Ta}[\%]$ & $\mathrm{Ni}[\%]$ & $\mathrm{Co}[\%]$ & $\mathrm{N}[\%]$ & $\mathrm{Mo}[\%]$ & $\mathrm{Nb}[\%]$ & $\mathrm{O}[\%]$ \\
\hline Cermet A & 40.4 & 20.1 & 9.5 & 11.9 & 5.9 & 5.3 & 4.3 & 1.3 & 1.2 & - \\
\hline Cermet B & 49.9 & 11.9 & 15.1 & - & 2.5 & 3.9 & - & 14.6 & - & 2.1 \\
\hline
\end{tabular}

Tab. 2 Specification of the cermet grade by suppliers

\begin{tabular}{|c|c|c|c|c|c|c|}
\hline Grade & $\begin{array}{c}\text { Density } \\
{\left[\mathrm{g} / \mathrm{cm}^{3}\right]}\end{array}$ & Hardness HRA & TRS $[\mathrm{MPa}]$ & Grain size $[\mu \mathrm{m}]$ & $\mathrm{K}_{\mathrm{IC}}\left[\mathrm{MPa}^{*} \mathrm{~m}^{1 / 2}\right]$ & $\begin{array}{c}\text { Classification } \\
\text { of ISO }\end{array}$ \\
\hline Cermet A & 7.12 & 92.5 & 1900 & - & - & $\begin{array}{c}\mathrm{P} 01-\mathrm{P} 10 \\
\mathrm{M} 01-\mathrm{M} 10\end{array}$ \\
\hline Cermet B & 6.40 & 91.8 & 2000 & $0.8-1.3$ & 8.5 & $\mathrm{~K} 05-\mathrm{K} 10$ \\
\hline
\end{tabular}

Tab. 3 Specification of the grinding wheel

\begin{tabular}{|c|c|c|c|c|c|}
\hline Wheel shape & Diameter $[\mathrm{mm}]$ & Width [mm] & Abrasive & Bond & Grain size \\
\hline 1A1 & 100 & 10 & Diamond & Resin-bond & D64 \\
\hline
\end{tabular}

Tab. 4 Cutting conditions

\begin{tabular}{|c|c|c|c|c|}
\hline Cutting speed $[\mathrm{m} / \mathrm{s}]$ & Feed rate $[\mathrm{mm} / \mathrm{min}]$ & Depth of cut $[\mathrm{mm}]$ & Grinding fluid & Strategy \\
\hline 20 & 30 & 0.5 & Mineral oil & Down grinding \\
\hline
\end{tabular}




\section{Grinding experiment and analysis}

Both cermet materials were ground by the same number of passes, the same strategy and cutting conditions. Truing of the diamond grinding wheel was carried out before the grinding experiment using a $\mathrm{SiC}$ wheel. Rotary truing of the wheel ensures the flat profile of the wheel. Dressing of the wheel was carried out after truing using an aluminium oxide stick to clean and open the grit of the grinding wheel. The surface of the diamond grinding wheel was scanned before the grinding experiment using an optical scanning device and an optical measuring device. As we can see, the surface of the dressed wheel is composed of sharp diamonds and clean binder (Fig. 2a).
The profile of the wheel was scanned during grinding using an optical measuring device to observe how the grinding wheel changes due to wheel wear.

Cermet A was ground using the described strategy. After several passes, the grinding process seems to be relatively quiet with just a little wheel loading. The spindle load which was monitored during grinding shows a value of $7.1 \%$. As the material removal volume increases, clogging of the wheel occurs and the diamonds of the grinding wheel begin to dull. After 130 passes, the surface of the grinding wheel is characterized by dull diamonds and clogging where some diamonds are ripped out of the bond. Dulling and clogging of the grinding wheel causes an increase in the spindle load during grinding which reaches a value of $11.7 \%$ at the end of the test (Fig. 2b).
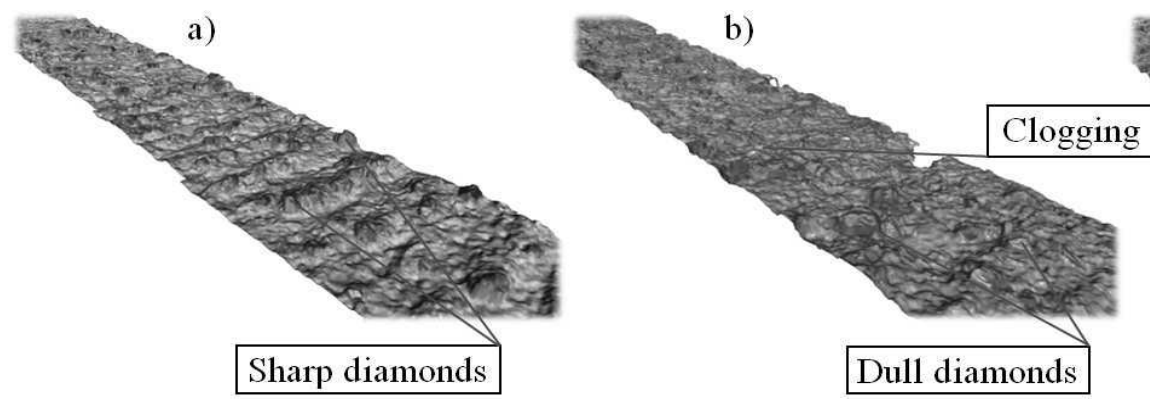

c)

Fig. 2 Surface of the grinding wheel: (a) new and (b) after 190 passes of grinding cermet A, and (c) cermet $B$

Cermet B is more difficult to grind than cermet A. During the first passes the spindle load reaches a value of $9.1 \%$. The spindle load increases with dulling and clogging of the grinding wheel. The whole process is accompanied by a pronounced acoustic emission as the material removal volume increases. Loading and clogging of the wheel is already significant at 70 passes of the wheel. The higher spindle load and wheel clogging causes diamonds to be gradually ripped out from the bonding of the grinding wheel. At the end of the experiment after 190 passes the grinding wheel is characterized by a dirty surface with significant clogging and ripped out diamonds (Fig. 2c). This grinding wheel degradation significantly affects the grinding ability and stability of the grinding process. Fig. 3 shows the progress of the spindle load of several passes to demonstrate the influence of degradation on the grinding stability. As we can see, the spindle load slowly increases with the number of passes until a certain value is reached. Then the spindle load decreases for one or more passes and then it increases again. These peaks in the spindle load show the changing of the grinding stability. As we can see, the spindle load reaches a value of over 15 $\%$ during pass number 166 when grinding cermet $\mathrm{B}$, and then the spindle load drops to $12.5 \%$ during the next pass (Fig. 3). There can be several reasons for this drop in the spindle load. It is assumed that an increase of the spindle load is caused by clogging of the grinding wheel during grinding. After reaching a greater amount of clogging, the weight of this stuck cermet material is high and it is removed by the coolant between passes. So the surface of the grinding wheel is partially cleaned by the pressure of the grinding fluid. This could be very problematic in the case of continuous grinding where there is no time between passes for cleaning the wheel. Another assumption of the spindle load decrease is that high load eventually causes breaking and pulling out of dull diamonds from the bond which leads to self-sharpening.

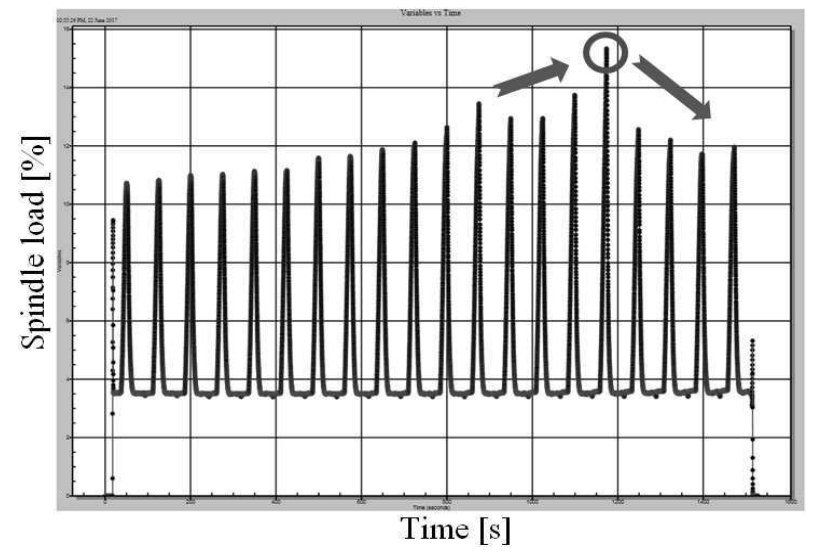

Fig. 3 Changes to the spindle load over several passes

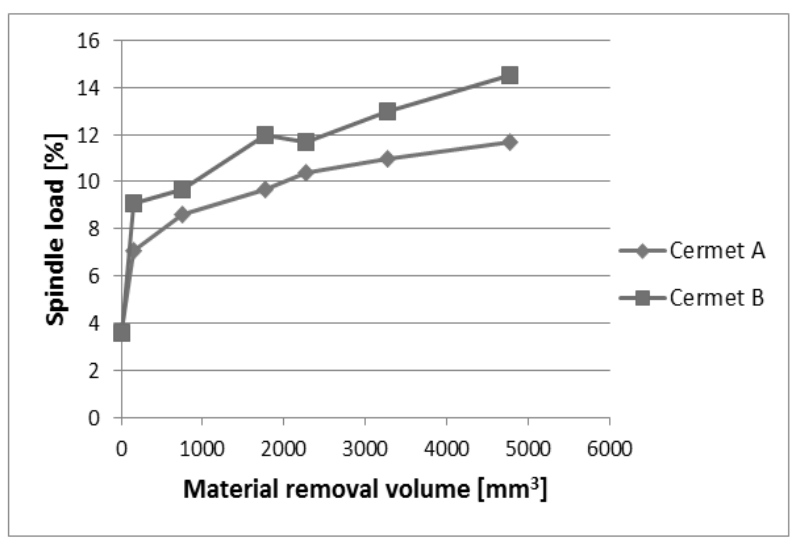

Fig. 4 Changes to the spindle load relative to material removal volume 
This change in the stability of the grinding process occurs when grinding both cermet materials. However, in the case of cermet A the stability starts to change after 130 passes, but for cermet B this change starts after only 40 passes. Fig. 4 shows how the spindle load increases with material removal volume.

The profile of the grinding wheel was scanned during the experiment using an optical measuring device to observe the grinding wheel wear and changes to the wheel shape. Tab. 5 shows the results of the measuring. Up to
70 passes there was no significant wheel wear for either cermet materials. After that, small wheel wear occurred and slightly increased up to a value of $28 \mu \mathrm{m}$ for cermet B. The wheel wear caused by cermet B was slightly higher than cermet $\mathrm{A}$, which corresponds to higher spindle load when grinding cermet B. It is necessary to point out that the grinding wheel was not trued or dressed during the tests, which leads to lower grinding wheel wear, but a higher spindle load and worse grinding ability was caused by the clogged and dull grinding wheel.

Tab. 5 Material removal volume and grinding wheel wear

\begin{tabular}{|c|c|c|c|c|}
\hline \multirow{2}{*}{ Number of passes } & \multirow{2}{*}{ Time in cut $[\mathrm{min}]$} & \multirow{2}{*}{$\begin{array}{c}\text { Material removal } \\
\text { volume }\left[\mathrm{mm}^{3}\right]\end{array}$} & \multicolumn{2}{|c|}{ Grinding wheel wear $[\mu \mathrm{m}]$} \\
\cline { 4 - 5 } & 1.6 & 150.8 & 3 & 6 \\
\hline 6 & 8 & 754 & 5 & 6 \\
\hline 30 & 18.7 & 1759.3 & 11 & 7 \\
\hline 70 & 24 & 2262 & 12 & 26 \\
\hline 130 & 34.7 & 3267.3 & 14 & 28 \\
\hline 190 & 50.7 & 4775.2 & 21 & Cermet A \\
\hline
\end{tabular}

The ground surface was observed during grinding in terms of surface roughness to determine the impact of grinding wheel degradation on the resulting surface quality. It was found that a higher spindle load and worse grinding ability of the wheel had no significant influence on the surface roughness in these tests. The surface roughness of cermet A was approximately the same during the whole grinding. Cermet B achieved a slightly lower surface roughness during the first 70 passes than cermet $\mathrm{A}$. After that, the roughness slightly increased and reached approximately the same value as for cermet A (Fig. 5). However, the surface was characterized by burning as a result of the greater load and clogging of the grinding wheel. Fig. 6 shows the scanned surfaces during the first passes and at the end of the tests of both materials. It can be observed that the ground surface after a few passes had more significant grinding marks than the surface at the end of the grinding, where the surface looked smoother. This could by caused by worse grinding ability due to clogging of the wheel and dulling of diamonds. The worse grinding ability leads to more rubbing between the grinding wheel and the ground surface instead of cutting. Despite the surface roughness being the same or similar at the end of the grinding, it is assumed that more rubbing and burn formation are connected with the higher temperature at the grinding point. This higher temperature could damage the surface in the form of micro-cracking or it could affect the surface properties in the form of residual stress.

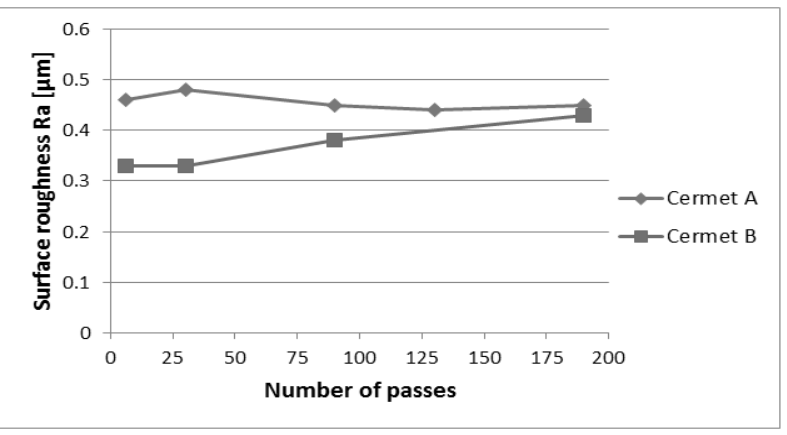

Fig. 5 Surface roughness during grinding

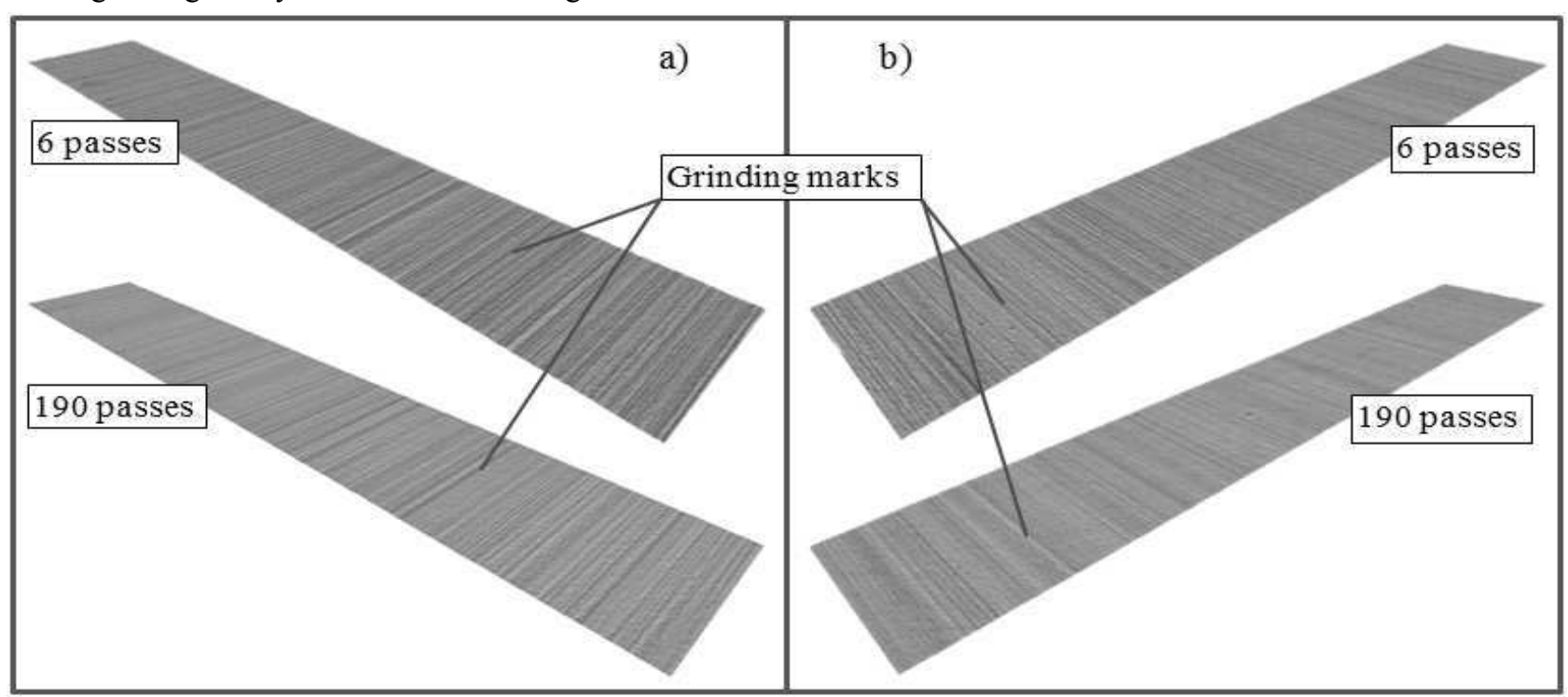

Fig. 6 Scanned surface after 6 and 190 passes of Cermet $A$ (a) and Cermet B (b) 


\section{Conclusions}

This research deals with the degradation of a grinding wheel during the grinding of two types of cermet materials. The surface of the grinding wheel was scanned before and during each test. It was found that both cermet grades caused clogging of the grinding wheel as the material removal volume increased. Dulling of the diamonds in the wheel also occurred after a certain number of passes. The spindle load was monitored during the test to observe the effect of wheel degradation on the grinding process. It was found that cermet B is more difficult to grind than cermet A. At the end of grinding cermet B the grinding wheel was characterized by large clogging and a high number of pulled out diamonds. This led to a loss of grinding ability which caused an increase of the spindle load to $15 \%$. Roughness of the ground surface was always around $\mathrm{Ra} 0.45 \mu \mathrm{m}$, but marks from burning and rubbing occurred, especially for cermet B. High spindle load and burn indicate a high temperature at the grinding point which could lead to residual stress and damage to the ground surface. Clogging and degradation of the grinding wheel could be reduced by in-process dressing, but this would probably lead to higher wheel wear and also to higher processing times. The second way to reduce grinding wheel degradation is to find appropriate grinding conditions. Therefore it is very important to better understand all aspects of grinding cermet.

\section{Acknowledgement}

This work has been prepared under project LO1502 'Development of the Regional Technological Institute' under the auspices of the National Sustainability Programme I of the Ministry of Education of the Czech Republic aimed at supporting research, experimental development and innovation.

\section{References}

[1] TAGLIABUE, F. (1991). Diamond grinding of cermets. In: Materials and Design, Vol. 12, pp. $209-212$.

[2] KURIYAGAWA, T., SYOJ, K., OHSHITA, H. (2003). Grinding temperature within contact arc between wheel and workpiece in high-efficiency grinding of ultrahard cutting tool materials. In: Journal of Materials Processing Technology, Vol. 136, pp. 39 - 47. Elsevier.

[3] KUMAR, K. (2002). Grinding Cermet Tool Materials. In: Ceramic Industry, Vol. 152, pp. 41.

[4] WEINERT, K., SCHNEIDER, M. (1999). Influence of the Grinding Process on the Process Beha- viour of Cutting Tools. In: Advanced manufacturing systems and technology, pp. 137 - 145, ISBN 978-3-7091-2508-3. Springer-Verlag Wien.

[5] WEINERT, K., SCHNEIDER, M. (2000). Simulation of Tool-Grinding with Finite Element Method. CIRP Annals - Manufacturing Technology, Vol. 49, pp. 253 - 256, Elsevier.

[6] KOCMAN, K. (2014). Influence of the Thermodynamic Phenomena on the Optimum Cutting Parameters in Grinding. In: Manufacturing Technology, Vol. 14, No. 1, pp. 34 - 41. ISSN 12132489.

[7] NOVAK, M. (2012). Surface with high precision of roughness after grinding. In: Manufacturing Technology, Vol. 12, No. 12, pp. 66 - 70. ISSN 1213-2489.

[8] ZHANG, Q., TO, S., ZHAO, Q., GUO, B. (2016). Surface damage mechanism of $\mathrm{WC} / \mathrm{Co}$ and $\mathrm{RB}-$ $\mathrm{SiC} / \mathrm{Si}$ composites under high spindle speed grinding (HSSG). In: Materials and Design, Vol. 92, pp. 378 - 386. Elsevier.

[9] GUO, B., ZHAO, Q., LI, H. (2014). Ultraprecision grinding of TiC-based cermet hemisphere couples. In: The International Journal of Advanced Manufacturing Technology, Vol. 73, pp. 1281 - 1289. Springer.

[10] KUNDRAK, J., FEDOROVICH, V., MARKOPOULOS, A. P., PYZHOV, I., KRYUKOVA, N. (2014). Improvements of the Dressing Process of Super Abrasive Diamond Grinding Wheels. In: Manufacturing Technology, Vol. 14, No. 4, pp. 545 - 554. ISSN 1213-2489.

[11] BAKSA, T., FARSKY, J., HRONEK, O., ZETEK, M. (2018). Influence of Depth of Cut on Quality of Ground Surface and Cutting Force when Grinding Cermet. In: Manufacturing Technology, Vol. 18, No. 3, pp. 352 - 356. ISSN 12132489.

[12] KUNDRAK, J., FEDOROVICH, V., PYZHOV, I., MARKOPOULOS, A. P., KLIMENKO, V., KRYUKOVA, N. (2017). Theoretical Analysis of the Contact Area between Grinding Wheel Surface and Workpiece in Flat Face Grinding with Spindle Axis Inclination. In: Manufacturing Technology, Vol. 17, No. 2, pp. 203 -210. ISSN 12132489.

[13] BAKSA, T., FARSKY, J., HRONEK, O., ZETEK, M. (2018). Impact of Cutting Speed on Grinding Wheel Wear and Cutting Force when Grinding Cermet. In: Manufacturing Technology, Vol. 18, No. 5, pp. 699 - 703. ISSN 1213-2489. 